\title{
Rapid and Sensitive Quantification of Intracellular Glycyl-Sarcosine for Semi-High-Throughput Screening for Inhibitors of PEPT-1
}

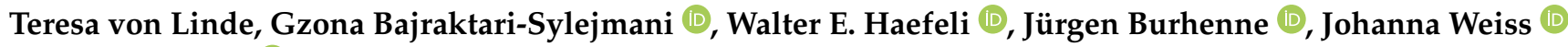 \\ and Max Sauter*(D)
}

\section{check for}

updates

Citation: von Linde, T.;

Bajraktari-Sylejmani, G.; Haefeli, W.E.;

Burhenne, J.; Weiss, J.; Sauter, M.

Rapid and Sensitive Quantification of

Intracellular Glycyl-Sarcosine for

Semi-High-Throughput Screening for Inhibitors of PEPT-1. Pharmaceutics

2021, 13, 1019. https://doi.org/

10.3390/pharmaceutics13071019

Academic Editors: Fiona McCartney and John Gleeson

Received: 7 May 2021

Accepted: 1 July 2021

Published: 3 July 2021

Publisher's Note: MDPI stays neutral with regard to jurisdictional claims in published maps and institutional affiliations.

Copyright: (C) 2021 by the authors Licensee MDPI, Basel, Switzerland. This article is an open access article distributed under the terms and conditions of the Creative Commons Attribution (CC BY) license (https:/ / creativecommons.org/licenses/by/ $4.0 /)$.
Department of Clinical Pharmacology and Pharmacoepidemiology, Heidelberg University Hospital, Im Neuenheimer Feld 410, 69120 Heidelberg, Germany; t.linde@stud.uni-heidelberg.de (T.v.L.); gzona.bajraktari-sylejmani@med.uni-heidelberg.de (G.B.-S.);

Walter-Emil.Haefeli@med.uni-heidelberg.de (W.E.H.); juergen.burhenne@med.uni-heidelberg.de (J.B.); johanna.weiss@med.uni-heidelberg.de (J.W.)

* Correspondence: max.sauter@med.uni-heidelberg.de; Tel.: +49-6221-56-32899
Abstract: The peptide transporter PEPT-1 (SLC15A1) plays a major role in nutritional supply with amino acids by mediating the intestinal influx of dipeptides and tripeptides generated during food digestion. Its role in the uptake of small bioactive peptides and various therapeutics makes it an important target for the investigation of the systemic absorption of small peptide-like active compounds and prodrug strategies of poorly absorbed therapeutics. The dipeptide glycyl-sarcosine (Gly-Sar), which comprises an $N$-methylated peptide bond that increases stability against enzymatic degradation, is widely utilized for studying PEPT-1-mediated transport. To support experiments on PEPT-1 inhibitor screening to identify potential substrates, we developed a highly sensitive Gly-Sar quantification assay for Caco-2 cell lysates with a dynamic range of 0.1 to $1000 \mathrm{ng} / \mathrm{mL}$ (lower limit of quantification $0.68 \mathrm{nM}$ ) in $50 \mu \mathrm{L}$ of cell lysate. The assay was validated following the applicable recommendations for bioanalytic method validation of the FDA and EMA. Sample preparation and quantification were established in 96-well cell culture plates that were also used for the cellular uptake studies, resulting in a rapid and robust screening assay for PEPT- 1 inhibitors. This sample preparation principle, combined with the high sensitivity of the UPLC-MS/MS quantification, is suitable for screening assays for PEPT-1 inhibitors and substrates in high-throughput formats and holds the potential for automation. Applicability was demonstrated by $\mathrm{IC}_{50}$ determinations of the known PEPT-1 inhibitor losartan, the known substrates glycyl-proline (Gly-Pro), and valaciclovir, the prodrug of aciclovir, which itself is no substrate of PEPT-1 and consequently showed no inhibition in our assay.

Keywords: PEPT-1; peptide transport; screening; tandem mass spectrometry; UPLC; glycyl-sarcosine

\section{Introduction}

The human peptide transporter PEPT-1 (SLC15A1) is predominantly expressed at the apical surface of enterocytes at the brush border membrane of the small intestine and mediates the uptake of dietary dipeptides and tripeptides [1-3]. PEPT-1 is a proton-dependent symporter, which translocates protons together with dipeptides and tripeptides, while the proton gradient is maintained by the sodium/hydrogen exchanger 3 (NHE3) [4-7]. As a high-capacity, low-affinity transporter, PEPT-1 has a high substrate promiscuity and accepts almost all physiological dipeptides and tripeptides as substrates with affinity constants mostly between 0.1 and $0.5 \mathrm{mM}[6,7]$. PEPT- 1 consists of 700-730 amino acids arranged in 12 transmembrane $\alpha$-helical domains that form a V-shaped transporter [6]. The transporter alternates in a scissor-like motion between an inward-open and outward-open confirmation to enable access to the central substrate binding site from different sides of the 
brush border membrane [8-10]. Besides its physiological importance in peptide uptake for nutritional supply with amino acids, PEPT-1 also affects the pharmacokinetic properties of small, peptide-like therapeutics by mediating their uptake from the intestinal lumen after oral administration [7]. Accordingly, systemic availability of several $\beta$-lactam antibiotics and angiotensin-converting enzyme inhibitors, as well as certain antiviral and antitumor agents, is attributed to PEPT-1 [7]. The low substrate selectivity makes all therapeutics that are structurally and sterically similar to dipeptides or tripeptides potential substrates of PEPT-1. Therefore, PEPT-1 is the subject of investigation into the systemic absorption of peptide-like drugs as well as in studies on associated drug-drug or food-drug interactions. Additionally, prodrug strategies targeting PEPT- 1 are an important approach to improve the oral bioavailability of sufficiently small, poorly absorbed therapeutics [11-17]. To support such medicinal chemistry prodrug developments and identify therapeutics that are potential PEPT-1 substrates likely to suffer from drug-drug or food-drug interactions during intestinal absorption, a rapid screening for PEPT-1 substrates is of high interest, favorably in high-throughput formats.

Because all PEPT-1 substrates are competitive inhibitors of the transporter, a first step in identifying PEPT-1 substrates is the evaluation of their inhibition of PEPT-1-mediated intracellular uptake of known specific substrates. These investigations may be followed by $\mathrm{IC}_{50}$ determinations to provide a robust evaluation of PEPT- 1 inhibition potency. To ensure that determined $\mathrm{IC}_{50}$ values of competitive inhibitors match the corresponding inhibitory constants $\left(K_{i}\right)$, the applied substrate concentration needs to substantially undercut the pertinent $K_{m}$, which necessitates highly sensitive quantification [18], especially when low cell numbers are used. To investigate PEPT-1-mediated transport, the determination of changes in the uptake of the dipeptide glycyl-sarcosine (Gly-Sar) has become the gold standard. Gly-Sar is particularly useful because of its high stability against intracellular degradation by ubiquitous di-peptidases, which results from $N$-methylation of the amide bond of the dipeptide. In addition, it has a sufficiently high affinity for PEPT- 1 with a $K_{m}$ of $860 \mu \mathrm{M}$ [19].

Due to the primary expression of PEPT- 1 in the intestinal brush border membrane, we considered the colorectal adenocarcinoma cell line Caco-2 a suitable cellular model to study PEPT-1 uptake. Previous studies have already demonstrated substantial PEPT-1 specific uptake of Gly-Sar in this cell line [12,20,21]. Further, Caco-2 cells form monolayers and subsequently undergo spontaneous enterocytic differentiation into a small intestinal phenotype and, therefore, are a popular model to study drug absorption in the gastrointestinal tract [22]. In addition, it has been demonstrated that Caco-2 cells express considerable levels of human PEPT-1 [23]. Typically, Caco-2 cells are cultured for approximately $21 \mathrm{~d}$ to reach a fully differentiated state exhibiting maximal but, at the same time, heterogeneous transporter expression [24-26].

Several quantification methods based on LC-MS for intracellular Gly-Sar have been reported previously $[20,26,27]$. The lowest previously reported lower limit of quantification (LLOQ) was $1 \mathrm{ng} / \mathrm{mL}$ in $50 \mu \mathrm{L}$ cell homogenate relying on cell experiments in formats down to 24-well plates [20]. These previously established methods all involved sample transfer steps of the cells or cell lysates to tubes, as well as sample workup with sonication or solvent evaporation rendering the sample processing relatively laborious. In the present study, we developed an assay for intracellular Gly-Sar quantification with an LLOQ of $0.1 \mathrm{ng} / \mathrm{mL}$ in $50 \mu \mathrm{L}$ of cell homogenate. We aimed at establishing a highly sensitive quantification for concurrently reducing the required number of cells in uptake studies and measure PEPT-1-mediated uptake shortly after monolayer formation (lower transporter expression), which considerably reduces required resources compared to previous methods. For this purpose, we developed a time-efficient sample preparation principle in 96-well formats, which allows for rapid and robust screening for PEPT-1 inhibitors in a semi-highthroughput scale without sample transfer. The feasibility of the assay for identification of PEPT-1 inhibitors was demonstrated by determining $\mathrm{IC}_{50}$ values of the known PEPT-1 
substrates glycyl-proline (Gly-Pro) and valaciclovir [21], the reported inhibitor losartan [28], and the lack of inhibition by the non-substrate parental compound of valaciclovir, aciclovir.

\section{Materials and Methods}

\subsection{Drugs, Chemicals, Solvents, and Materials}

Caco-2 cells were provided by the American Type Culture Collection (Manassas, VA, USA). Dulbecco's modified Eagle's Medium (DMEM), MEM non-essential amino acid solution (NEAS), fetal bovine serum (FBS), penicillin-streptomycin, L-glutamine solution, Dulbecco's phosphate-buffered saline (PBS), trypsin-EDTA solution, Gly-Sar, GlyPro, Boc-Gly-OSu, and 2-(N-morpholino)ethanesulfonic acid (MES) were obtained from Sigma-Aldrich (Munich, Germany). Losartan potassium was purchased from Santa Cruz Biotechnology (Dallas, TX, USA) and $\left[{ }^{13} \mathrm{C}_{3}\right]$-sarcosine from Toronto Research Chemicals (North York, ON, Canada). Ammonia solution (25\%), N,N-dimethylformamide (DMF), and trifluoroacetic acid (TFA) were obtained from Merck (Darmstadt, Germany). tert-butyl methyl ether (TBME) was provided by VWR International (Darmstadt, Germany). Purified water was produced using an arium ${ }^{\circledR}$ mini (Sartorius, Göttingen, Germany) ultrapure water system. Remaining reagents and solvents, methanol (MeOH), acetonitrile (ACN), and formic acid (FA) were purchased from Biosolve (Valkenswaard, The Netherlands) in the highest purity available. Aprotinin and pepstatin A were purchased from AppliChem (Darmstadt, Germany), leupeptin, aciclovir, and valaciclovir hydrochloride were obtained from Biomol (Hamburg, Germany), whereas pefabloc was received from Carl Roth (Karlsruhe, Germany). RIPA lysis and extraction buffer and the Pierce ${ }^{\mathrm{TM}} \mathrm{BCA}$ protein assay kit were purchased from Thermo Fisher Scientific (Darmstadt, Germany). All other chemicals were obtained from Sigma-Aldrich (Munich, Germany) if not stated otherwise.

\subsection{Cell Culture and Inhibition Experiments}

Caco- 2 cells were cultivated in DMEM supplemented with $10 \%$ FBS, glutamine $(2 \mathrm{mM})$, penicillin $(100 \mathrm{U} / \mathrm{mL})$, streptomycin $(100 \mu \mathrm{g} / \mathrm{mL})$, and $1 \%$ NEAS. They were kept at $37^{\circ} \mathrm{C}$ and $5 \% \mathrm{CO}_{2}$ and passaged once a week. For validation and uptake experiments, cells were seeded in 96-well plates at a density of $6.25 \times 10^{4} \mathrm{cells} / \mathrm{cm}^{2}$ and allowed to differentiate for at least $7 \mathrm{~d}$ to ensure sufficient PEPT-1 expression. The uptake buffer (MES) was prepared as previously described by Sun et al. [29] and contained $50 \mathrm{mM} \mathrm{MES,} 136.9 \mathrm{mM} \mathrm{NaCl}$, $5.4 \mathrm{mM} \mathrm{KCl}, 1.26 \mathrm{mM} \mathrm{CaCl}_{2}, 0.81 \mathrm{mM} \mathrm{MgSO}_{4} \times 7 \mathrm{H}_{2} \mathrm{O}, 0.5 \mathrm{mM} \mathrm{Na}_{2} \mathrm{HPO}_{4}, 0.44 \mathrm{mM}$ $\mathrm{KH}_{2} \mathrm{PO}_{4}, 0.42 \mathrm{mM} \mathrm{NaHCO}$, and $5.54 \mathrm{mM}$ glucose. The $\mathrm{pH}$ value of the uptake buffer was adjusted to $\mathrm{pH}=6.0$ using either $\mathrm{HCl}$ or $\mathrm{NaOH}$ solutions. Gly-Sar uptake was tested after 7,24 , and 28 d of Caco-2 cell differentiation. Because no substantial increase in Gly-Sar uptake was observed after longer differentiation times, uptake and competition studies were conducted after $7 \mathrm{~d}$ cultivation. For inhibition studies, cells were washed with MES buffer $(100 \mu \mathrm{L} /$ well) once and uptake was initiated by the addition of $0.1-5000 \mu \mathrm{M}$ losartan, 10-50,000 $\mu \mathrm{M}$ Gly-Pro, 0.1-5000 $\mu \mathrm{M}$ acyclovir, or 1-50,000 $\mu \mathrm{M}$ valaciclovir followed by $20 \mu \mathrm{M}$ Gly-Sar, all prepared in MES buffer. After an incubation period of $10 \mathrm{~min}$ at $37^{\circ} \mathrm{C}$ under gentle agitation, transport was terminated by removing the solution and washing the cells with ice-cold MES buffer (100 $\mu \mathrm{L} /$ well) thrice while the plate was kept on ice. Afterwards, cells were lysed in the 96-well cell culture plate with aqueous $\mathrm{NH}_{4} \mathrm{OH}(10 \%$, $50 \mu \mathrm{L} /$ well) and sample preparation was performed as described below.

\subsection{Protein Quantification}

Protein quantification was conducted using the Pierce ${ }^{\mathrm{TM}}$ BCA Protein Assay Kit according to the manufacturer's instructions. The kit is based on the well-known Biuret reaction, in which copper ions are reduced by proteins. In a second step, two molecules of the added bicinchoninic acid (BCA) chelate the reduced copper cation producing a complex with intense purple color, which was measured spectrophotometrically at a wavelength of $555 \mathrm{~nm}$ with a SpectraMax ID3 (Molecular Devices, Munich, Germany). The BCA reaction precisely measures the total protein content in lysates extrapolated from a calibration curve 
obtained by diluting BSA to create standards. The calibration ranged from 0 to $2000 \mu \mathrm{g}$ protein $/ \mathrm{mL}$ with a detection limit of $5 \mu \mathrm{g} / \mathrm{mL}$. In brief, Caco- 2 cells were grown confluent for at least $7 \mathrm{~d}$ on a 96-well plate. On the day of the measurement, 20 wells in five different columns of the plate were chosen randomly. Cells were washed with warm MES buffer and then lysed with $100 \mu \mathrm{L}$ cold RIPA buffer with added protease inhibitors. For cell lysis, samples were kept on ice for $30 \mathrm{~min}$ and then centrifuged at $4{ }^{\circ} \mathrm{C}$ for $15 \mathrm{~min}$ at $15,000 \mathrm{~g}$. $50 \mu \mathrm{L}$ of the supernatant was used for measurement and each sample was measured in duplicate.

\subsection{Synthesis of the Internal Standard Glycyl- $\left[{ }^{13} C_{3}\right]$-Sarcosine}

To synthesize the internal standard (IS) glycyl- $\left[{ }^{13} \mathrm{C}_{3}\right]$-sarcosine, isotopically labeled $\left[{ }^{13} \mathrm{C}_{3}\right]$-sarcosine, and Boc-glycine $\mathrm{N}$-hydroxysuccinimid-ester (Boc-Gly-OSu), the $\mathrm{N}$ protected derivative of glycine with an NHS-ester activated carboxylic terminus were used. In brief, $\left[{ }^{13} \mathrm{C}_{3}\right]$-sarcosine and Boc-Gly-OSu were dissolved in a $1 / 1(v / v)$ mixture of phosphate buffer $(\mathrm{pH}=8.0)$ and $N, N$-dimethylformamide (DMF) and stirred overnight at room temperature. The first lyophilization resulted in a concentrated solution; therefore, the reaction product was extracted with TBME and water followed by another lyophilization step. Afterwards, the Boc-protective group was removed by treatment with a TFA solution containing $5 \%$ water $(v / v)$ for $2 \mathrm{~h}$. The dipeptide was precipitated by addition of a 20 -fold excess of TBME, and subsequently washed with the similar amount of TBME $(30 \mathrm{~mL})$. The identity of the newly synthesized glycyl- $\left[{ }^{13} \mathrm{C}_{3}\right]$-sarcosine was confirmed by high-resolution mass spectrometry on a Xevo G2-XS QTof mass spectrometer (Waters, Milford, MA, USA) with a Z-Spray ESI source using the integrated direct infusion system. The measured mass at $m / z 150.0971$ was in good agreement with the theoretical value of $\mathrm{m} / \mathrm{z} 150.0958$ (mass error $8.7 \mathrm{ppm}$ ). The IS exhibits a mass difference of $3 \mathrm{Da}$ compared to the analyte, Gly-Sar. The obtained glycyl- $\left[{ }^{13} \mathrm{C}_{3}\right]$-sarcosine solution was diluted 100-fold in $\mathrm{H}_{2} \mathrm{O} / \mathrm{ACN}(95 / 5$, $v / v)+0.1 \%$ FA to prepare the IS stock solution.

\subsection{Preparation of Standard and Quality Control Samples}

Calibration and quality control (QC) stock solutions were obtained by separately weighing Gly-Sar in $5 \mathrm{~mL}$ volumetric flasks and accurately dissolving it in $\mathrm{H}_{2} \mathrm{O} / \mathrm{ACN}$ $(95 / 5, v / v)+0.1 \%$ formic acid (FA). The stock solutions were then diluted 100 -fold with $\mathrm{H}_{2} \mathrm{O} / \mathrm{ACN}(95 / 5, v / v)+0.1 \% \mathrm{FA}$ and used to prepare calibration standard spike solutions at concentrations of $1,3,10,30,100,300,1000,3000$, and 10,000 ng/mL, which corresponds to sample concentrations of $0.1,0.3,1,3,10,30,100,300$, and $1000 \mathrm{ng} / \mathrm{mL}$. QC spike solutions were prepared accordingly and diluted to 1 (LLOQ), 3 (low QC), 600 (mid QC), and $7500 \mathrm{ng} / \mathrm{mL}$ (high QC), which corresponds to QC sample concentrations of 0.1, 0.3, 60, and $750 \mathrm{ng} / \mathrm{mL}$. To obtain the IS spike solution, the IS stock solution was diluted 100-fold in $\mathrm{H}_{2} \mathrm{O} / \mathrm{ACN}(95 / 5, v / v)+0.1 \%$ FA and further diluted 100-fold in $\mathrm{ACN} / \mathrm{H}_{2} \mathrm{O}(9 / 1, v / v)+$ $0.1 \%$ FA.

\subsection{Sample Preparation}

Sample preparation was performed directly in the 96-well cell culture plates. Cell lysates $(50 \mu \mathrm{L})$ were spiked with $25 \mu \mathrm{L}$ IS spike solution and, depending on the sample type, with either $5 \mu \mathrm{L}$ of the respective calibration or QC solution (calibration and QC samples) or with $5 \mu \mathrm{L} \mathrm{H}_{2} \mathrm{O} / \mathrm{ACN}(95 / 5, v / v)+0.1 \%$ FA for volume compensation (study samples). Subsequently, all samples were filled with $180 \mu \mathrm{L} \mathrm{ACN}+0.1 \%$ FA for protein precipitation and centrifuged for $10 \mathrm{~min}$ at $800 \mathrm{~g}$. Finally, the 96-well plates were transferred into the Sample Manager for direct injection onto the UPLC-MS/MS system.

\subsection{Instrumental Analysis Parameters}

The quantification of Gly-Sar in cell homogenates was performed on a UPLC-MS/MS system consisting of a triple-stage quadrupole mass spectrometer (Waters Xevo TQ-XS with Z-spray ESI source) and an Acquity Classic UPLC®(Waters, Milford, MA, USA). 
Chromatographic separation was achieved on a Waters Cortecs UPLC®HILIC column $(90 \AA, 1.6 \mu \mathrm{m}, 2.1 \times 50 \mathrm{~mm})$ heated to $60{ }^{\circ} \mathrm{C}$ with the injection volume set to $10 \mu \mathrm{L}$ and a flow rate of $0.4 \mathrm{~mL} / \mathrm{min}$. The mobile phase consisted of $\mathrm{H}_{2} \mathrm{O} / \mathrm{ACN}(95 / 5, v / v)+0.1 \%$ FA (aqueous eluent; A) and ACN + 0.1\% FA (ACN eluent; B). Gly-Sar was eluted with an isocratic composition of $16 \% \mathrm{~A} / 84 \% \mathrm{~B}$ for $3 \mathrm{~min}$. Subsequently, the conditions were changed to $50 \% \mathrm{~A} / 50 \% \mathrm{~B}$ within $0.5 \mathrm{~min}$ and maintained for $0.5 \mathrm{~min}$ to flush the column. Afterwards, the initial ratio of $16 \% \mathrm{~A}$ and $84 \% \mathrm{~B}$ was restored during $0.5 \mathrm{~min}$. The mass spectrometer was operated using an electrospray ionization (ESI) source in the positive ion detection mode. Quantification of Gly-Sar and IS was performed by selected reaction monitoring (SRM) using argon collision gas for collision-induced dissociation (CID). Mass spectrometric parameters were optimized for the detection of Gly-Sar and the IS using the auto-optimization feature IntelliStart of the MassLynx V4.2 system software (Waters, Milford, MA, USA). Optimized mass spectrometric conditions are shown in Table 1.

Table 1. Optimized parameters for the MS/MS detection of glycyl-sarcosine and glycyl- $\left[{ }^{13} C_{3}\right]-$ sarcosine in positive heated ESI and SRM.

\begin{tabular}{cc}
\hline Parameter & Gly-Sar (glycyl-[13 $\left.\mathrm{C}_{3}\right]$-sarcosine) \\
\hline Spray voltage & $0.5 \mathrm{kV}$ \\
Cone voltage & $30 \mathrm{~V}$ \\
Cone gas flow & $150 \mathrm{~L} / \mathrm{Hr}$ \\
Source temperature & $150{ }^{\circ} \mathrm{C}$ \\
Desolvation gas flow $\left(\mathrm{N}_{2}\right)$ & $1000 \mathrm{~L} / \mathrm{h}$ \\
Desolvation temperature & $500{ }^{\circ} \mathrm{C}$ \\
MRM transition $(m / \mathrm{z})$ & $100 \mathrm{~ms}$ \\
Dwell time & $10 \mathrm{~V}$ \\
Collision energy & $0.15 \mathrm{~mL} / \mathrm{min}$ \\
\hline Collision gas flow (Ar)
\end{tabular}

ESI, electrospray ionization; SRM, selected reaction monitoring.

\subsection{Method Validation}

The assay to quantify Gly-Sar in cell homogenates was validated following the EMA and FDA guidelines on bioanalytical method validation [30,31]. For this purpose, the linearity, accuracy, precision, selectivity, stability, recovery, and matrix effect of the assay were determined in three validation batches, which included eight calibration samples in duplicates and 24 QC samples at four concentrations (LLOQ, low, mid, and high QC) in sixfold determination. Accuracy (\%) is the degree of agreement between the determined value and known true value and was subsequently determined by dividing the quantified mean concentration by the nominal concentration. Precision (\% CV) describes the degree of agreement between individual measurements of the same analyte and was calculated by dividing the standard deviation by the quantified mean of the measurements. Chromatograms of blank cell lysate samples from six different cell passage numbers and of corresponding spiked samples were assessed for interfering signals at the retention time of Gly-Sar and IS to determine the selectivity of the method. Cell culture plates were used for sample preparations and UPLC-MS/MS analyses without any transfer or extraction of samples. Recovery was evaluated for low, mid, and high QC concentration of Gly-Sar by the comparison of peak areas of QC samples spiked after extraction with the respective peak areas of blank plasma samples spiked after extraction. Matrix effects were determined for low, mid, and high QC concentration of Gly-Sar by the comparison of peak areas of blank plasma samples spiked after extraction with the respective peak areas of matrix-free solvent spiked with the identical amount. Recovery was measured by the comparison of peak areas of QC samples (low, mid, and high) to peak areas of blank plasma samples spiked with the respective amount after extraction. Stability of Gly-Sar in cell lysate was evaluated over the course of $24 \mathrm{~h}$ by comparing peak areas of stored samples with their initial values. Gly-Sar integrity was further evaluated in the spike solutions. 


\subsection{Calculations and Statistical Methods}

Calibration curves were fitted by the Waters TargetLynx V4.2 software (Waters, Milford, MA, USA) using $1 / x^{2}$-weighted linear regressions of the peak area ratios of Gly-Sar and the IS. General calculations were performed using Microsoft Excel 2010 (Mountain View, CA, USA). IC $_{50}$ values (i.e., the inhibitor concentration, which causes a baselinenormalized half-maximal Gly-Sar uptake) were calculated using the GraphPad Prism 9 software (version 9.1.0; GraphPad Software Inc., La Jolla, CA, USA). Intracellular Gly-Sar concentrations at varying inhibitor concentrations were fitted with nonlinear regression to a four-parameter concentration-response curve (4PL) according to the equation:

$$
y=\text { bottom }+\frac{\text { Top }- \text { Bottom }}{1+\left(\frac{\text { IC50 }}{x}\right)^{\text {Hillslope }}}
$$

where $y=$ intracellular Gly-Sar concentration and $x=$ inhibitor concentration.

\section{Results}

\subsection{Mass Spectrometric and Chromatographic Characteristics}

Positive electrospray ionization of Gly-Sar $\left(\mathrm{C}_{5} \mathrm{H}_{10} \mathrm{~N}_{2} \mathrm{O}_{3}, 146.14 \mathrm{Da}\right)$ predominantly formed the $[\mathrm{M}+\mathrm{H}]^{+}$precursor ion of Gly-Sar at $\mathrm{m} / \mathrm{z} 147.0$ and $\mathrm{m} / \mathrm{z} 150.0$ for the IS. Due to the protonation of the amino terminus of the dipeptide in acidic conditions, Gly-Sar exhibits favorable sensitivity in positive ion mode. During optimization of CID, we investigated the four most intense mass transitions $(\mathrm{m} / \mathrm{z}): 147.0 \rightarrow 90.0\left(\mathrm{y}_{1}\right), 147.0 \rightarrow 105.9\left(\mathrm{z}_{1}\right), 147.0$ $\rightarrow 129.0$ (non-specific $\mathrm{H}_{2} \mathrm{O}$-loss), and $147.0 \rightarrow 101.0$ ( $\alpha$-cleavage of the $\mathrm{C}$-terminus that equals non-specific $\mathrm{CO}$ and $\mathrm{H}_{2} \mathrm{O}$ loss). Based on its superior intensity and low endogenous background, the selective mass transition of $m / z 147.0 \rightarrow 90.0$ was chosen for Gly-Sar quantification using SRM. For the IS, the corresponding mass transition of $\mathrm{m} / \mathrm{z} 150.0$ $\rightarrow 93.0$ was monitored. The $N$-methylation of the amide bond of Gly-Sar is crucial for sensitive SRM because the non-methylated analog of the monitored fragment, glycine, similar to most single amino acid product ions, usually shows very high background in cell homogenates. Figure 1 depicts the investigated dissociations of Gly-Sar and the IS. Mass spectrometric conditions were optimized during method development and are listed in Table 1.

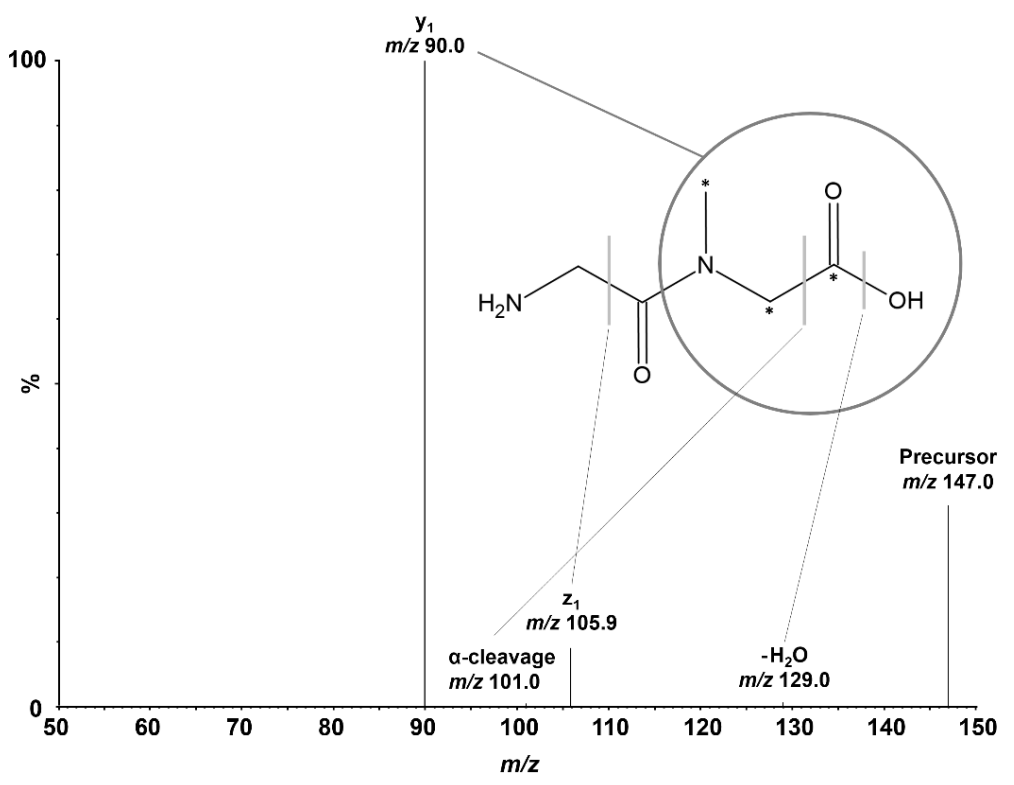

Figure 1. Product ion spectrum of Gly-Sar at a collision energy of $10 \mathrm{~V}$. The structure of Gly-Sar with the positions of the isotopic label in the internal standard marked with asterisks is also depicted. The four investigated dissociation locations are marked by gray bars or a circle, with the circle showing the monitored $\mathrm{y}_{1}$-fragment. 
Gly-Sar was chromatographically separated from endogenous substances on a Waters Cortecs HILIC UPLC ${ }^{\circledR}$ column $(90 \AA$ A, $1.6 \mu \mathrm{m}, 2.1 \times 50 \mathrm{~mm})$ using isocratic elution at a composition of $16 \%$ aqueous eluent and $84 \%$ ACN eluent, which was most efficient in separating endogenous interferences (Figure 2). The method gave reproducible retention times and peak shapes with a width at baseline of $24 \mathrm{~s}$. Representative UPLC chromatograms of cell homogenates with varying Gly-Sar concentrations (blank sample, blank sample spiked with IS, LLOQ, mid QC, and a study sample after 10 min incubation with $20 \mu \mathrm{M}$ Gly-Sar and $1 \mathrm{mM}$ losartan) are presented in Figure 2.

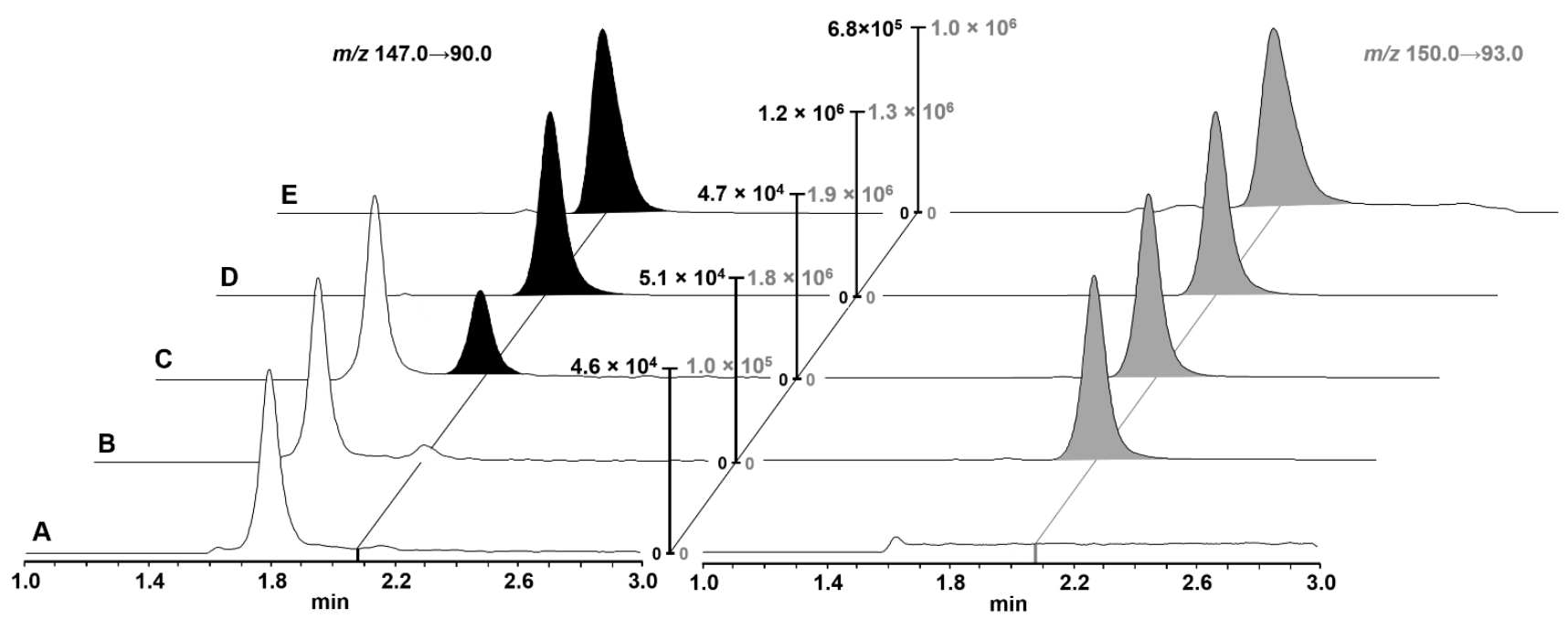

Figure 2. Representative UPLC-MS/MS chromatograms of Gly-Sar in cell lysates. Gly-Sar transition is shown on the left (black filling), and the IS transition is shown on the right (gray filling). Intensities were normalized to the highest signal in the current run: (A) blank sample; (B) blank lysate with added IS; (C) sample at LLOQ concentration; (D) sample at mid QC concentration; (E) intracellular Gly-Sar concentration after incubation with $20 \mu \mathrm{M}$ Gly-Sar and $1 \mathrm{mM}$ losartan for 10 min (quantified Gly-Sar concentration: $23.9 \mathrm{ng} / \mathrm{mL}$ ).

\subsection{Sample Preparation}

To minimize matrix effects and ensure sensitive and specific quantification of Gly-Sar with reproducible chromatographic characteristics, different sodium-free lysis methods were tested. Cell lysis with $10 \% \mathrm{NH}_{4} \mathrm{OH}$ yielded cell homogenates with the lowest viscosity and highest signal intensity compared with lysis using methanol, $1 \%$ aqueous triton- $X$, or $0.1 \mathrm{~N}$ hydrochloric acid. Unexpectedly, lysate neutralization proved detrimental to sensitivity, likely due to a resulting high salinity. Sample clean-up was performed with protein precipitation, which was achieved by the addition of $180 \mu \mathrm{L}$ ACN and subsequent centrifugation. After sample processing, the cell culture plates were directly inserted into the sample manager for Gly-Sar quantification. Because peak areas of samples stored in the autosampler showed $<15 \%$ deviation from the initial values, we considered Gly-Sar stable during the course of analysis. In addition, Gly-Sar was found stable in spike solutions for at least 9 months, demonstrated by accuracy deviations of $<10 \%$ of QC solutions prepared from a fresh weighing that were quantified with stored calibration solutions.

\subsection{Validation Results}

The newly developed assay for quantification of intracellular Gly-Sar was validated in compliance with the applicable sections of the FDA and EMA recommendations for bioanalytical method validation [30,31]. No interferences $>20 \%$ of the LLOQ peak area or $>5 \%$ of the IS peak area were observed, demonstrating the selectivity of the assay. Linearity was achieved over four orders of magnitude from 0.1 to 1,000 ng/mL, with correlation coefficients $\left(r^{2}\right)>0.99$ for all calibration curves. Accuracy and precision were consistent with the pertinent EMA and FDA recommendations and are summarized in Table 2. 
Table 2. Quality control results of the validation.

\begin{tabular}{|c|c|c|c|c|c|}
\hline & & $\begin{array}{c}\text { LLOQ } \\
0.100 \mathrm{ng} / \mathrm{mL}\end{array}$ & $\begin{array}{c}\text { Low QC } \\
0.300 \mathrm{ng} / \mathrm{mL}\end{array}$ & $\begin{array}{c}\text { Mid QC } \\
60.0 \mathrm{ng} / \mathrm{mL}\end{array}$ & $\begin{array}{c}\text { High QC } \\
750 \mathrm{ng} / \mathrm{mL}\end{array}$ \\
\hline \multicolumn{6}{|c|}{ Within-Batch } \\
\hline \multirow{3}{*}{1} & Mean [ng/mL] & 0.116 & 0.311 & 54.3 & 703 \\
\hline & Accuracy [\%] & 116.0 & 103.7 & 90.6 & 93.8 \\
\hline & Precision [\%CV] & 0.704 & 3.52 & 3.84 & 2.76 \\
\hline \multirow{3}{*}{2} & Mean [ng/mL] & 0.106 & 0.312 & 59.2 & 715 \\
\hline & Accuracy [\%] & 106.0 & 104.0 & 98.7 & 95.4 \\
\hline & Precision $[\% \mathrm{CV}]$ & 6.05 & 4.13 & 2.87 & 0.854 \\
\hline \multirow{3}{*}{3} & Mean [ng/mL] & 0.107 & 0.312 & 56.7 & 691 \\
\hline & Accuracy [\%] & 107.0 & 104.0 & 94.4 & 92.2 \\
\hline & Precision $[\% \mathrm{CV}]$ & 10.3 & 9.96 & 3.71 & 1.81 \\
\hline \multicolumn{6}{|c|}{ Batch-to-Batch } \\
\hline & Mean [ng/mL] & 0.110 & 0.311 & 56.8 & 702 \\
\hline & Accuracy [\%] & 110.0 & 103.7 & 94.6 & 93.6 \\
\hline & Precision $[\% \mathrm{CV}]$ & 7.47 & 5.77 & 4.93 & 2.36 \\
\hline
\end{tabular}

$\mathrm{CV}$, coefficient of variation; LLOQ, lower limit of quantification; $\mathrm{QC}$, quality control; $N=4$ replicates at LLOQ and each QC concentration.

No carryover was observed after eluent injections following the highest calibration samples. Recovery of the protein precipitation was consistently high, ranging from 75.1 to $83.4 \%$ for low to high QC and the IS, while the matrix effects were also consistent over the entire range tested, and were between $29 \%$ and $35 \%$; both parameters showed corresponding precisions of $\leq 10 \%$. The substantial matrix effect is likely induced by the high ammonium and phospholipid content of the processed cell lysate samples. However, the concurrent high sensitivity of the Gly-Sar quantification compensates for the intensity loss from the matrix effect caused by the rapid and well-manageable sample processing.

Normalized to the IS, recoveries and matrix effects were well within required limits, with values from 99.0 and $101.1 \%$ and 102.1 and 106.1, respectively.

\subsection{Application: Inhibition of Gly-Sar Uptake by Gly-Pro, Losartan, Valaciclovir, and Aciclovir}

To demonstrate the applicability of our assay for screening of PEPT-1 inhibitors, the effect of Gly-Pro, losartan, valaciclovir, and aciclovir on Gly-Sar uptake was investigated. Protein determination across wells of the 96-well plate verified a highly consistent protein content per well of $64.2 \pm 1.8 \mu \mathrm{g}$, which corresponds to a variation in protein amount of only $\pm 2.8 \%$. Caco-2 cells were incubated with $20 \mu \mathrm{M}$ Gly-Sar in absence and with increasing amounts of the investigated compounds. Because of the substantial transport rate of PEPT1, intracellular Gly-Sar concentrations were determined after the shortest incubation period that was well manageable, which we regarded to be $10 \mathrm{~min}$. PEPT- 1 inhibition properties for Gly-Pro, losartan, valaciclovir, and aciclovir were determined in three independent experiments, each comprising at least quadruplet measurements. Determined $\mathrm{IC}_{50}$ values were converted to $K_{i}$ values using the $\mathrm{IC}_{50}$-to- $\mathrm{K}_{\mathrm{i}}$ tool [18], assuming competitive inhibition and a $K_{m}$ of $860 \mu \mathrm{M}$ for Gly-Sar [19]. At $\mathrm{pH}=6.0$, we observed a concentration-dependent inhibition of Gly-Sar uptake for Gly-Pro, losartan, and valaciclovir. In contrast, aciclovir did not interfere with Gly-Sar uptake (Figure 3). The determined IC $_{50}$ values for Gly-Pro, losartan, and valaciclovir were $257 \pm 28 \mu \mathrm{M}, 45.1 \pm 15.8 \mu \mathrm{M}$, and $894 \pm 309 \mu \mathrm{M}$, respectively. These correspond to calculated $K_{i}$ values of $250 \mu \mathrm{M}, 44 \mu \mathrm{M}$, and $874 \mu \mathrm{M}$, respectively. 

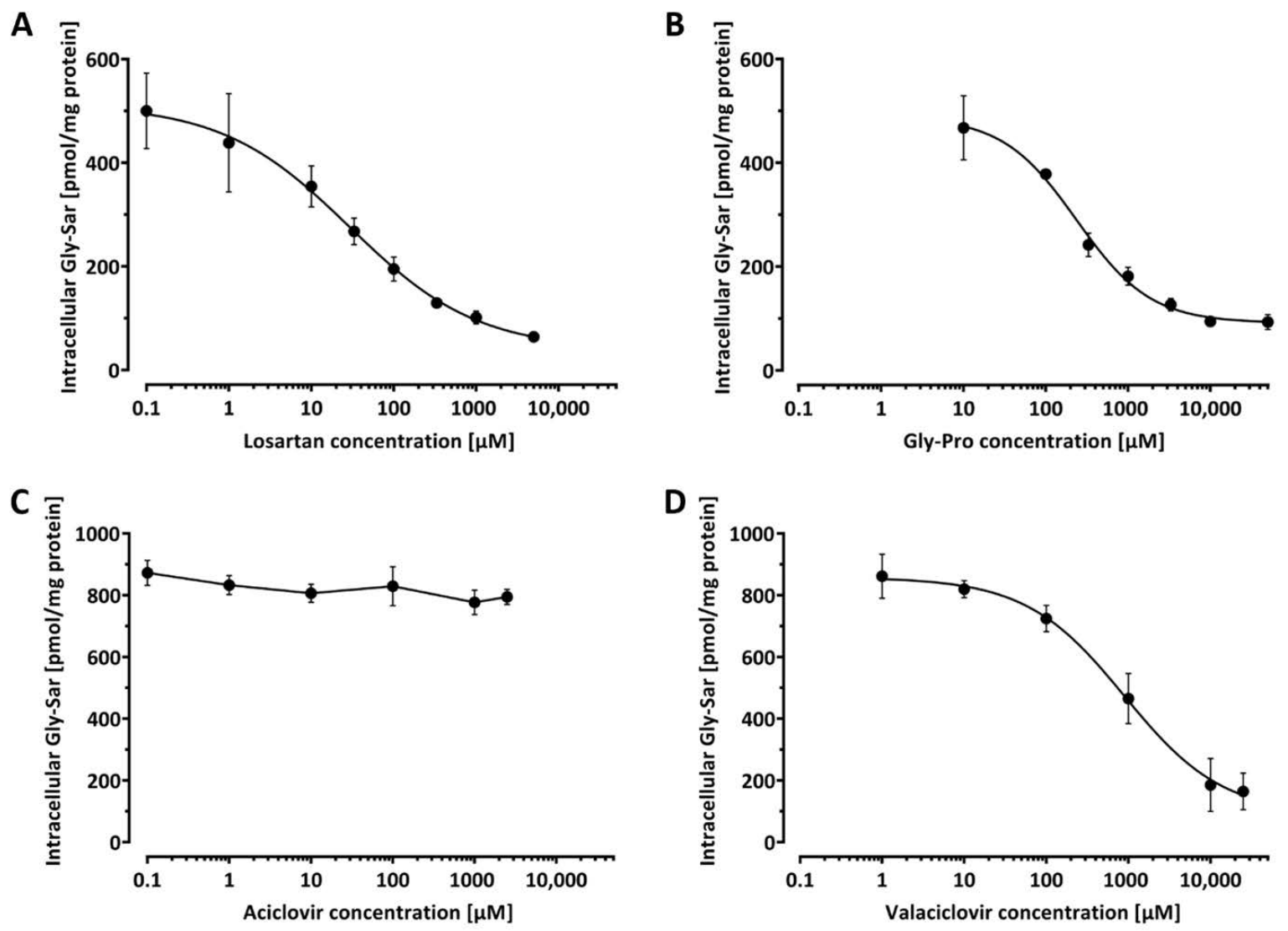

Figure 3. Concentration-response curves on Caco-2 cells for the inhibition of PEPT-1 mediated transport of $20 \mu \mathrm{M}$ Gly-Sar by losartan (A), Gly-Pro (B), aciclovir (C), and valaciclovir (D). Each data point is a mean of three independent experiments, each experiment performed at least in quadruplet determination.

\section{Discussion}

Oral drug administration is the preferred route for therapeutics due to its convenience for patients and safe self-administration. However, consistent absorption is an essential prerequisite for oral therapeutics. The simplest way to avoid a high variability in exposure is a high bioavailability. PEPT-1 is a high-capacity transporter highly abundant in the intestine. Therefore, substrates thereof are likely to achieve high intestinal absorption and, as a consequence, high oral bioavailabilities. Small molecule therapeutics may be rendered PEPT-1 substrates by using prodrug approaches relying on chemical modification. Such prodrug developments are especially viable due to the high substrate promiscuity of PEPT-1. Prominent examples for such prodrug developments are the antiviral therapeutics valaciclovir and valganciclovir. These are ester conjugates of the respective parental antiviral drugs and the amino acid valine that exhibit substantially increased oral bioavailabilities due to their absorption via PEPT-1 [12,21,32]. For the purpose of such prodrug developments of poorly absorbed small molecule therapeutics, an efficient identification of PEPT-1 substrates is highly beneficial, especially for screening chemical compound libraries and medicinal chemistry approaches with a high number of test substances. Because all substrates of PEPT- 1 are competitive inhibitors of the transporter, determination of their inhibitory properties can be used as a surrogate for substrate screening.

Our developed UPLC-MS/MS assay for intracellular Gly-Sar quantification fulfills the necessary requirements for supporting efficient PEPT- 1 inhibitor screenings. In comparison to previously published methods, it is a magnitude more sensitive while concurrently avoiding laborious sample processing and especially sample transfer steps. In contrast to previous methods, we ensured reliable quantification by using an isotopically labeled analog of Gly-Sar as IS that efficiently balanced matrix effects and recovery of the sample 
processing. This was verified by the very low deviation of the IS-normalized matrix effects and recovery. Our established sample processing directly performed in the cell culture plates renders the assay very rapid and well manageable in high-throughput formats and may even be suitable for automation. However, we consider this methodology as semi-high throughput because the sequential mass spectrometric analysis limits the overall analysis rate. Further, due to the high sensitivity of the quantification assay, the required number of cells in uptake studies can be lowered substantially, which considerably reduces the required resources in regard to cell culture and the especially important required amount of test substance of potential inhibitors. Further, the used Caco-2 cells form monolayers, a characteristic that results in an equal cell number across the wells of the 96-well plate, facilitating accurately comparable results. We could demonstrate this by the measurement of a highly consistent protein content per well. The deviation between wells was very low $(<3 \%)$ and can be considered neglectable, especially considering the anticipated systematic error of the detection method. As a consequence, if normalization to protein amount is necessary for comparison to other studies, determination of the protein content of few wells can serve for that purpose. In screening experiments, this consistent cell content allows for accurate comparisons of inhibitory power between tested compounds.

We demonstrated the feasibility of our assay for PEPT- 1 inhibitor screens by determining the $\mathrm{IC}_{50}$ of the four compounds Gly-Pro (dipeptide substrate), losartan (high-affinity inhibitor), valaciclovir (prodrug substrate), and aciclovir (non-substrate) with high replicate numbers, which was facilitated by the used 96-well format. The calculated $K_{i}$ values of $44 \mu \mathrm{M}, 250 \mu \mathrm{M}$, and $874 \mu \mathrm{M}$ agreed reasonably well with reported $K_{i}$ values of $24 \mu \mathrm{M}$ [28], $300 \mu \mathrm{M}$ [33], and $740 \mu \mathrm{M}$ [21], for losartan, Gly-Pro, and valaciclovir, respectively. Moreover, as expected, the non-substrate aciclovir did no inhibit the Gly-Sar uptake in our assay. This clearly demonstrates that our newly developed assay is suitable for rapid and well-manageable screening for PEPT-1 inhibitors and further applicable to determinations of pertinent $\mathrm{IC}_{50}$ values in high-throughput formats.

Throughout all measured $\mathrm{IC}_{50}$ determinations, the ratios of bottom to top of the fitted sigmoidal curves were similar, with a mean of $14.0 \pm 6.7 \%$. This non-inhibited (non-PEPT-1 specific) Gly-Sar uptake may source from passive uptake via diffusion or macropinocytosis or may result from amino acid transporters for which Gly-Sar is a substrate such as hPAT1 (SLC36A1) [34]. However, the majority of Gly-Sar uptake (around $86 \%$ ) is PEPT-1 mediated, which is consistent with previous reports [21]. Nevertheless, short incubation times may be essential in avoiding extensive non-PEPT-1 specific uptake of Gly-Sar. Previous studies showed that Gly-Sar uptake approaches saturation shortly beyond $10 \mathrm{~min}[26,35]$. However, incubation times shorter than $10 \mathrm{~min}$ increase assay intrinsic errors and are not well manageable. Thus, we chose $10 \mathrm{~min}$ in our assay and due to the high fraction of Gly-Sar uptake that was specific for PEPT-1 in our setting, we regard this incubation time feasible for inhibitor screening.

\section{Conclusions}

We established a highly sensitive intracellular Gly-Sar quantification assay with robust and reliable quantification due to a chemically synthesized isotopically labeled analog as IS. Because of the assay's high sensitivity, simple and rapid sample processing was established directly in 96-well plates used for cell culture, evading laborious sample workup and transfer steps. This sample preparation procedure is, therefore, suitable to assess PEPT1 inhibitor properties in high-throughput formats and the assay can serve as a screening tool for potential PEPT-1 substrates.

Author Contributions: Conceptualization, G.B.-S. and M.S.; methodology, M.S.; validation, T.v.L.; G.B.-S.; W.E.H.; J.B.; J.W. and M.S.; formal analysis, M.S.; investigation, T.v.L.; G.B.-S. and M.S.; resources, W.E.H.; J.B. and J.W.; writing—original draft preparation, T.v.L.; writing—review and editing, G.B.-S.; J.W. and M.S.; visualization, T.v.L. and M.S.; project administration, J.W. and M.S.; funding acquisition, W.E.H. and M.S. All authors have read and agreed to the published version of the manuscript. 
Funding: This project was funded in part by the German Federal Ministry of Education and Research (BMBF; grant number 03VP03980); MS and GB were supported in part by the Physician Scientist Program of the Faculty of Medicine of Heidelberg University.

Institutional Review Board Statement: Not applicable.

Informed Consent Statement: Not applicable.

Data Availability Statement: The data are available from the corresponding author upon reasonable request.

Acknowledgments: The authors thank Corina Mueller and Stephanie Rosenzweig for their technical assistance.

Conflicts of Interest: The authors declare no conflict of interest.

\section{References}

1. Groneberg, D.; Döring, F.; Eynott, P.R.; Fischer, A.; Daniel, H. Intestinal peptide transport: Ex vivo uptake studies and localization of peptide carrier PEPT1. Am. J. Physiol. Gastrointest. Liver Physiol. 2001, 281, G697-G704. [CrossRef] [PubMed]

2. Walker, D.; Thwaites, D.T.; Simmons, N.L.; Gilbert, H.J.; Hirst, B.H. Substrate upregulation of the human small intestinal peptide transporter, hPepT1. J. Physiol. 1998, 507 Pt 3, 697-706. [CrossRef]

3. Wuensch, T.; Schulz, S.; Ullrich, S.; Lill, N.; Stelzl, T.; Rubio-Aliaga, I.; Loh, G.; Chamaillard, M.; Haller, D.; Daniel, H. The peptide transporter PEPT1 is expressed in distal colon in rodents and humans and contributes to water absorption. Am. J. Physiol. Gastrointest. Liver Physiol. 2013, 305, G66-G73. [CrossRef]

4. Brandsch, M. Transport of drugs by proton-coupled peptide transporters: Pearls and pitfalls. Expert Opin. Drug Metab. Toxicol. 2009, 5, 887-905. [CrossRef] [PubMed]

5. Newstead, S. Recent advances in understanding proton coupled peptide transport via the POT family. Curr. Opin. Struct. Biol. 2017, 45, 17-24. [CrossRef]

6. Rubio-Aliaga, I.; Daniel, H. Peptide transporters and their roles in physiological processes and drug disposition. Xenobiotica 2008, 38, 1022-1042. [CrossRef]

7. Spanier, B.; Rohm, F. Proton Coupled Oligopeptide Transporter 1 (PepT1) Function, Regulation, and Influence on the Intestinal Homeostasis. Compr. Physiol. 2018, 8, 843-869. [PubMed]

8. Fowler, P.W.; Orwick-Rydmark, M.; Radestock, S.; Solcan, N.; Dijkman, P.; Lyons, J.A.; Kwok, J.; Caffrey, M.; Watts, A.; Forrest, L.R.; et al. Gating Topology of the Proton-Coupled Oligopeptide Symporters. Structure 2015, 23, 290-301. [CrossRef] [PubMed]

9. Minhas, G.S.; Newstead, S. Recent advances in understanding prodrug transport through the SLC15 family of proton-coupled transporters. Biochem. Soc. Trans. 2020, 48, 337-346. [CrossRef] [PubMed]

10. Solcan, N.; Kwok, J.; Fowler, P.; Cameron, A.; Drew, D.; Iwata, S.; Newstead, S. Alternating access mechanism in the POT family of oligopeptide transporters. EMBO J. 2012, 31, 3411-3421. [CrossRef]

11. Perry, C.M.; Faulds, D. Valaciclovir: A review of its antiviral activity, pharmacokinetic properties and therapeutic efficacy in herpesvirus infections. Drugs 1996, 52, 754-772. [CrossRef]

12. Sugawara, M.; Huang, W.; Fei, Y.; Leibach, F.H.; Ganapathy, V.; Ganapathy, M.E. Transport of Valganciclovir, a Ganciclovir Prodrug, via Peptide Transporters PEPT1 and PEPT2. J. Pharm. Sci. 2000, 89, 781-789. [CrossRef]

13. Sun, Y.; Sun, J.; Shi, S.; Jing, Y.; Yin, S.; Chen, Y.; Li, G.; Xu, Y.; He, Z. Synthesis, Transport and Pharmacokinetics of $5^{\prime}$-Amino Acid Ester Prodrugs of 1- $\beta$-d-Arabinofuranosylcytosine. Mol. Pharm. 2008, 6, 315-325. [CrossRef] [PubMed]

14. Gupta, D.; Gupta, S.V.; Dahan, A.; Tsume, Y.; Hilfinger, J.; Lee, K.-D.; Amidon, G.L. Increasing Oral Absorption of Polar Neuraminidase Inhibitors: A Prodrug Transporter Approach Applied to Oseltamivir Analogue. Mol. Pharm. 2013, 10, 512-522. [CrossRef]

15. Sun, Y.; Gan, W.; Lei, M.; Jiang, W.; Cheng, M.; He, J.; Sun, Q.; Liu, W.; Hu, L.; Jin, Y. PEPT1-mediated prodrug strategy for oral delivery of peramivir. Asian J. Pharm. Sci. 2018, 13, 555-565. [CrossRef] [PubMed]

16. Wang, C.-L.; Fan, Y.-B.; Lu, H.-H.; Tsai, T.-H.; Tsai, M.-C.; Wang, H.-P. Evidence of d-phenylglycine as delivering tool for improving l-dopa absorption. J. Biomed. Sci. 2010, 17, 71. [CrossRef]

17. Yan, Z.; Sun, J.; Chang, Y.; Liu, Y.; Fu, Q.; Xu, Y.; Sun, Y.; Pu, X.; Zhang, Y.; Jing, Y.; et al. Bifunctional Peptidomimetic Prodrugs of Didanosine for Improved Intestinal Permeability and Enhanced Acidic Stability: Synthesis, Transepithelial Transport, Chemical Stability and Pharmacokinetics. Mol. Pharm. 2011, 8, 319-329. [CrossRef]

18. Cer, R.Z.; Mudunuri, U.; Stephens, R.; Lebeda, F.J. IC50-to-Ki: A web-based tool for converting IC50 to Ki values for inhibitors of enzyme activity and ligand binding. Nucleic Acids Res. 2009, 37, W441-W445. [CrossRef]

19. Hu, Y.; Chen, X.; Smith, D.E. Species-dependent uptake of glycylsarcosine but not oseltamivir in Pichia pastoris expressing the rat, mouse, and human intestinal peptide transporter PEPT1. Drug Metab. Dispos. 2012, 40, 1328-1335. [CrossRef] 
20. Sun, Y.; Sun, J.; Liu, J.; Yin, S.; Chen, Y.; Zhang, P.; Pu, X.; Sun, Y.; He, Z. Rapid and sensitive hydrophilic interaction chromatography/tandem mass spectrometry method for the determination of glycyl-sarcosine in cell homogenates. J. Chromatogr. B 2009, 877, 649-652. [CrossRef]

21. Ganapathy, M.E.; Huang, W.; Wang, H.; Ganapathy, V.; Leibach, F.H. Valacyclovir: A Substrate for the Intestinal and Renal Peptide Transporters PEPT1 and PEPT2. Biochem. Biophys. Res. Commun. 1998, 246, 470-475. [CrossRef]

22. Meunier, V.; Berger, Y.; Fabre, G. The human intestinal epithelial cell line Caco-2; pharmacological and pharmacokinetic applications. Cell Biol. Toxicol. 1995, 11, 187-194. [CrossRef] [PubMed]

23. Ruiz, D.H.; Wang, Q.; Cook, T.J.; Knipp, G.T.; Gudmundsson, O.S.; Smith, R.L.; Faria, T.N. Spatial expression patterns of peptide transporters in the human and rat gastrointestinal tracts, Caco-2 In Vitro cell culture model, and multiple human tissues. AAPS PharmSci 2001, 3, 100-111. [CrossRef] [PubMed]

24. Behrens, I.; Kissel, T. Do cell culture conditions influence the carrier-mediated transport of peptides in Caco-2 cell monolayers? Eur. J. Pharm. Sci. 2003, 19, 433-442. [CrossRef]

25. Vachon, P.H.; Beaulieu, J.-F. Transient mosaic patterns of morphological and functional differentiation in the Caco-2 cell line Gastroenterology 1992, 103, 414-423. [CrossRef]

26. Guo, X.; Meng, Q.; Liu, Q.; Wang, C.; Huo, X.; Zhang, Z.; Kaku, T.; Liu, K. Simultaneous determination of three dipeptides (JBP485, Gly-Sar and JBP923) in the cell lysates by liquid chromatography-tandem mass spectrometry: Application to identify the function of the PEPT1 transfected cell. Biomed. Chromatogr. 2014, 28, 1839-1845. [CrossRef]

27. Guo, X.; Meng, Q.; Liu, Q.; Wang, C.; Sun, H.; Kaku, T.; Liu, K. Construction, identification and application of HeLa cells stably transfected with human PEPT1 and PEPT2. Peptides 2012, 34, 395-403. [CrossRef]

28. Knütter, I.; Kottra, G.; Fischer, W.; Daniel, H.; Brandsch, M. High-Affinity Interaction of Sartans with H+/Peptide Transporters. Drug Metab. Dispos. 2009, 37, 143-149. [CrossRef] [PubMed]

29. Sun, D.; Wang, Y.; Tan, F.; Fang, D.; Hu, Y.; Smith, D.E.; Jiang, H. Functional and Molecular Expression of the Proton-Coupled Oligopeptide Transporters in Spleen and Macrophages from Mouse and Human. Mol. Pharm. 2013, 10, 1409-1416. [CrossRef] [PubMed]

30. US Department of Health and Human Services, Food and Drug Administration, Guidance for Industry, Bioanalytical Method Validation, 2018. Available online: www.fda.gov/downloads/Drugs/GuidanceComplianceRegulatoryInformation/Guidances/ ucm070107.pdf (accessed on 3 May 2021).

31. Committee for Medicinal Products for Human Use, European Medicines Agency, Guideline on Validation of Bioanalytical Methods, 2009, EMEA/CHMP/EWP/192217/2009. Available online: http:/ /www.ema.europa.eu/docs/enGB/documentlibrary/ Scientificguideline/2011/08/WC500109686.pdf (accessed on 3 May 2021).

32. Yang, B.; Smith, D.E. Significance of peptide transporter 1 in the intestinal permeability of valacyclovir in wild-type and PepT1 knockout mice. Drug Metab. Dispos. 2012, 41, 608-614. [CrossRef]

33. Brandsch, M.; Knutter, I.; Thunecke, F.; Hartrodt, B.; Born, I.; Börner, V.; Hirche, F.; Fischer, G.; Neubert, K. Decisive structural determinants for the interaction of proline derivatives with the intestinal $\mathrm{H}+$ /peptide symporter. JBIC J. Biol. Inorg. Chem. 1999, 266, 502-508. [CrossRef] [PubMed]

34. Frølund, S.; Holm, R.; Brodin, B.; Nielsen, C.U. The proton-coupled amino acid transporter, SLC36A1 (hPAT1), transports Gly-Gly, Gly-Sar and other Gly-Gly mimetics. Br. J. Pharmacol. 2010, 161, 589-600. [CrossRef] [PubMed]

35. Ma, K.; Hu, Y.; Smith, D.E. Peptide Transporter 1 Is Responsible for Intestinal Uptake of the Dipeptide Glycylsarcosine: Studies in Everted Jejunal Rings from Wild-type and Pept1 Null Mice. J. Pharm. Sci. 2011, 100, 767-774. [CrossRef] [PubMed] 